\title{
A framework for estimating the US mortality burden of fine particulate matter exposure attributable to indoor and outdoor microenvironments
}

\author{
Parham Azimi ${ }^{1} \cdot$ Brent Stephens $^{1}$
}

Received: 23 January 2018 / Revised: 25 September 2018 / Accepted: 12 November 2018 / Published online: 5 December 2018

(c) The Author(s) 2018. This article is published with open access

\begin{abstract}
Exposure to fine particulate matter $\left(\mathrm{PM}_{2.5}\right)$ is associated with increased mortality. Although epidemiology studies typically use outdoor $\mathrm{PM}_{2.5}$ concentrations as surrogates for exposure, the majority of $\mathrm{PM}_{2.5}$ exposure in the US occurs in microenvironments other than outdoors. We develop a framework for estimating the total US mortality burden attributable to exposure to $\mathrm{PM}_{2.5}$ of both indoor and outdoor origin in the primary non-smoking microenvironments in which people spend most of their time. The framework utilizes an exposure-response function combined with adjusted mortality effect estimates that account for underlying exposures to $\mathrm{PM}_{2.5}$ of outdoor origin that likely occurred in the original epidemiology populations from which effect estimates are derived. We demonstrate the framework using several different scenarios to estimate the potential magnitude and bounds of the US mortality burden attributable to total $\mathrm{PM}_{2.5}$ exposure across all nonsmoking environments under a variety of assumptions. Our best estimates of the US mortality burden associated with total $\mathrm{PM}_{2.5}$ exposure in the year 2012 range from $\sim 230,000$ to $\sim 300,000$ deaths. Indoor exposure to $\mathrm{PM}_{2.5}$ of outdoor origin is typically the largest total exposure, accounting for $\sim 40-60 \%$ of total mortality, followed by residential exposure to indoor $\mathrm{PM}_{2.5}$ sources, which also drives the majority of variability in each scenario.
\end{abstract}

Keywords criteria pollutants $\cdot$ epidemiology $\cdot$ exposure modeling $\cdot$ inhalation exposure $\cdot$ particulate matter

\section{Introduction}

Elevated outdoor concentrations of fine particulate matter (i.e., the mass concentration of particles $\leq 2.5 \mu \mathrm{m}$ in aerodynamic diameter; $\mathrm{PM}_{2.5}$ ) have been consistently associated with increased mortality in numerous epidemiology studies [1-9]. Although epidemiology studies typically use centrally monitored outdoor $\mathrm{PM}_{2.5}$ concentrations as surrogates for average human exposures to $\mathrm{PM}_{2.5}$ of outdoor origin, the majority of exposure to $\mathrm{PM}_{2.5}$ of outdoor origin in the US and other industrialized nations typically occurs in various

Supplementary material The online version of this article (https:// doi.org/10.1038/s41370-018-0103-4) contains supplementary material, which is available to authorized users.

Brent Stephens

brent@iit.edu

1 Department of Civil, Architectural, and Environmental Engineering, Illinois Institute of Technology, Chicago, IL, USA other microenvironments, including inside residences, offices, schools, and vehicles [10-16]. This is because people spend the majority of their time in microenvironments other than outdoors $[17,18]$ and outdoor $\mathrm{PM}_{2.5}$ can infiltrate and persist into different microenvironments with varying efficiencies [19-24]. There are also many $\mathrm{PM}_{2.5}$ sources present in non-smoking indoor microenvironments, including cooking [25-27], burning incense and candles [28, 29], operating office equipment $[30,31]$, resuspension from settled dust from human activities such as walking and cleaning [32, 33], and secondary organic aerosols from oxidation reactions [34]. To date, the vast majority of air pollution epidemiology studies and quantitative risk assessments have not explicitly accounted for these varied microenvironmental exposures [35, 36].

The objective of this work is to develop a framework for estimating the total US mortality burden attributable to exposure to $\mathrm{PM}_{2.5}$ of both indoor and outdoor origin in the primary non-smoking microenvironments in which people spend most of their time. The framework primarily utilizes a modified version of an exposure-response function 
commonly used for air pollution risk assessment combined with adjusted mortality effect estimates that account for estimates of underlying microenvironmental exposures to $\mathrm{PM}_{2.5}$ of outdoor origin that likely occurred in prior epidemiology cohort studies. We demonstrate the utility of the framework by conducting several scenario analyses to estimate the likely magnitude and bounds of the US mortality burden associated with long-term $\mathrm{PM}_{2.5}$ exposures that result from both indoor and outdoor PM sources in each microenvironment. While no single model scenario is considered to be the definitive representation of the US mortality burden of microenvironmental $\mathrm{PM}_{2.5}$ exposures due to unique data limitations in each case, each model scenario offers insight into how the framework can be used with richer data sets in the future to refine nationwide mortality estimates and ultimately to inform policy decisions to reduce exposures in the microenvironments in which they most often occur.

\section{Materials and methods}

\section{Selection of an appropriate exposure-response function}

Integral to the model framework is the selection of an appropriate health impact function. A number of recent air pollution risk assessments have estimated mortality and/or morbidity associated with ambient $\mathrm{PM}_{2.5}$ exposure in various locations using different forms of health impact functions and associated effect estimates derived from epidemiology studies. Historically, most studies have used a variant of a generic exposure-response health impact function for ambient air pollution [37] to estimate a population's change in health endpoint $\left(\Delta y_{i}\right)$ due to a change in the assumed population-average exposure to pollutant $i\left(\Delta E_{i}\right)$ (e.g., Eq. 1).

$\Delta y_{i}=y_{0}\left[\exp \left(\beta_{i} \times \Delta E_{i}\right)-1\right]$ Pop

where $y_{0}$ is the annual baseline prevalence of illness (per person per year), $\beta_{i}$ is the health endpoint effect estimate for pollutant $i$ resulting from prior epidemiology studies (e.g., per $\mu \mathrm{g} / \mathrm{m}^{3}$ of pollutant $\left.i\right), \Delta E_{i}$ is the change in exposure concentration relative to an assumed baseline or threshold concentration (e.g., $\mu \mathrm{g} / \mathrm{m}^{3}$ of pollutant $i$, typically assuming outdoor concentrations are surrogates for exposure), and Pop is size of the affected population. This approach has been used recently to estimate the mortality burden associated with outdoor $\mathrm{PM}_{2.5}$ concentrations in the US [38-42] and globally [43, 44]. For example, Fann et al. (2017) [42] used this approach with all-cause mortality effect estimates from Krewski et al. (2009) [5] to estimate that 120,000 deaths (95\% CI: 83,000-160,000) were associated with outdoor $\mathrm{PM}_{2.5}$ exposures in the in 2010 . Fann et al. (2017) [42] also made another estimate of 200,000 (95\% CI: 43,000-1,100,000) deaths associated with outdoor $\mathrm{PM}_{2.5}$ using a different model form and effect estimates from Nasari et al. (2016) [45]. Similar approaches have also recently been extended to estimate the chronic health burden associated with long-term indoor PM exposures using effect estimates taken directly from the outdoor air epidemiology literature [46-50].

Another widely used approach to air pollution risk assessment is the Global Burden of Disease (GBD) study's integrated exposure-response (IER) methodology [51-56], and its follow-up Global Exposure Mortality Model (GEMM) [57], which were developed in part because the generic expression in Eq. 1 is based on epidemiology cohort studies in the US and Europe with outdoor $\mathrm{PM}_{2.5}$ concentrations (typically below $30 \mu \mathrm{g} / \mathrm{m}^{3}$ ) that may not be representative for countries with much higher ambient air pollution levels [53] or for other, higher, $\mathrm{PM}_{2.5}$ exposures such as secondhand or active smoking. Here we primarily utilize a modified version of the generic exposure-response health impact function in Eq. 1 for the model framework because (a) it was developed for use with epidemiology studies with $\mathrm{PM}_{2.5}$ concentrations within the range of concern in non-smoking indoor and outdoor microenvironments in the US, (b) there is considerable uncertainty in the shape of the GBD IER function and its fitted parameters at lower $\mathrm{PM}_{2.5}$ concentrations most relevant to this study, and (c) it has been used successfully in other recent indoor microenvironmental exposure investigations. However, we also apply the IER model and evaluate its utility in the SI.

\section{Modifying the exposure-response function}

We modify the exposure-response function in Eq. 1 for $\mathrm{PM}_{2.5}$ in a manner similar to that in Logue et al. (2012) [48] to account for microenvironmental $\mathrm{PM}_{2.5}$ concentrations and exposures, albeit with a few additional modifications as shown in Eq. 2. First, we introduce a modified form of $\beta_{i}$ for ambient-generated $\mathrm{PM}_{2.5}$ (i.e., $\beta_{P M 2.5, A G \text {,modified }}$ ) to account for estimates of the underlying long-term average exposures to $\mathrm{PM}_{2.5}$ of outdoor origin that likely occurred in various microenvironments in the cohort populations used in the original epidemiology studies from which $\beta_{P M 2.5}$ was derived. This modification provides an adjusted effect estimate for outdoor $\mathrm{PM}_{2.5}$ based on estimates of long-term average microenvironmental exposures that can be more universally applied to other microenvironmental exposure estimates rather than using outdoor $\mathrm{PM}_{2.5}$ concentrations alone as a surrogate for exposure.

Second, we separately account for long-term average $\mathrm{PM}_{2.5}$ exposures above an assumed threshold concentration in each microenvironment $j$ that result from ambient- 
generated sources $\left(\Delta C_{P M 2.5, A G, j}\right)$ and indoor-generated sources $\left(\Delta C_{P M 2.5, I G, j}\right)$. Third, $t_{j}$ accounts for the average fraction of time spent in a particular microenvironment $j$. Thus, the sums of $\Delta C_{P M 2.5, A G, j} \times t_{j}$ and $\Delta C_{P M 2.5, I G, j} \times t_{j}$ across all microenvironments more realistically account for total $\mathrm{PM}_{2.5}$ exposure $\left(\Delta E_{P M 2.5}\right)$ from both indoor and outdoor sources. Finally, we also allow for using different assumptions for modified mortality effect estimates for ambient-generated and indoor-generated $\mathrm{PM}_{2.5}$ (i.e., $\beta_{P M 2.5 \text {, }}$ ${ }_{A G \text {,modified }}$ and $\beta_{P M 2.5, I G, \text { modified, }}$ respectively). Although the framework can account for varying toxicity of ambient- and indoor-generated $\mathrm{PM}_{2.5}$, we assume equal toxicity here because of conflicting conclusions among the limited number of studies that have investigated differential toxicity using paired indoor, outdoor, and/or personal PM samples [58-63].

$$
\begin{array}{r}
\Delta y_{P M 2.5}=y_{0}\left[\operatorname { e x p } \left(\beta_{P M 2.5, I G, \text { modified }} \times \sum_{j}\left(\Delta C_{P M 2.5, I G, j} \times t_{j}\right)\right.\right. \\
\left.\left.+\beta_{P M 2.5, A G, \text { modified }} \times \sum_{j}\left(\Delta C_{P M 2.5, A G, j} \times t_{j}\right)\right)-1\right] \text { Pop }
\end{array}
$$

We consider four main microenvironments in which people are exposed to $\mathrm{PM}_{2.5}$ of both indoor and outdoor origin: (i) inside residences, (ii) inside indoor environments other than residences (e.g., schools, business, restaurants, etc.), (iii) inside vehicles, and (iv) outdoors. Equation 3 shows modified forms of the $\Sigma\left(\Delta C_{P M 2.5, I G, j} \times t_{j}\right)$ and $\Sigma\left(\Delta C_{P M 2.5, A G, j} \times t_{j}\right)$ terms in Eq. 2 that account for the long-term average $\mathrm{PM}_{2.5}$ concentrations resulting from both indoor and outdoor sources and the average fraction of time spent inside each of these four primary microenvironments.

$$
\begin{gathered}
\sum_{j}\left(\Delta C_{P M 2.5, I G, j} \times t_{j}\right)=\left(\Delta C_{P M 2.5, I G, \text { residences }} \times t_{\text {residences }}\right) \\
+\left(\Delta C_{P M 2.5, I G, \text { other indoor }} \times t_{\text {other indoor }}\right)
\end{gathered}
$$

$$
\begin{gathered}
\sum_{j}\left(\Delta C_{P M 2.5, A G, j} \times t_{j}\right)=\left(\Delta C_{P M 2.5, A G, \text { residences }} \times t_{\text {residences }}\right) \\
+\left(\Delta C_{P M 2.5, A G, \text { other indoor }} \times t_{\text {other indoor }}\right) \\
+\left(\Delta C_{P M 2.5, A G, \text { vehicles }} \times t_{\text {vehicles }}\right)+\left(\Delta C_{P M 2.5, \text { outdoor }} \times t_{\text {outdoor }}\right)
\end{gathered}
$$

where $\Delta C_{P M 2.5, I G, \text { residences }}$ and $\Delta C_{P M 2.5, I G \text {,other indoor }}$ are the differences in long-term average concentrations of indoorgenerated $\mathrm{PM}_{2.5}$ in non-smoking residences and all other non-smoking indoor environments other than residences, respectively, both compared to a baseline value in which there are no indoor $\mathrm{PM}_{2.5}$ sources $\left(\mu \mathrm{g} / \mathrm{m}^{3}\right) ; \Delta C_{P M 2.5, A G \text {, }}$ residences, $\Delta C_{P M 2.5, A G \text {,other indoor }}$, and $\Delta C_{P M 2.5, A G \text {,vehicles }}$ are the differences in long-term average concentrations of ambientgenerated $\mathrm{PM}_{2.5}$ in residences, indoor environments other than residences, and vehicles, respectively, compared to a baseline value $\left(\mu \mathrm{g} / \mathrm{m}^{3}\right) ; \Delta C_{P M 2.5 \text {, outdoor }}$ is the difference in long-term average outdoor $\mathrm{PM}_{2.5}$ concentrations also compared to a baseline value $\left(\mu \mathrm{g} / \mathrm{m}^{3}\right)$; and $t_{\text {residences }}, t_{\text {other }}$ indoor,$t_{\text {vehicles }}$, and $t_{\text {outdoor }}$ are the long-term average fractions of time spent inside each microenvironment, respectively. Note that Eq. 3a assumes there are no indoor sources of $\mathrm{PM}_{2.5}$ inside vehicles, primarily because of a lack of comprehensive surveys of in-vehicle PM sources, although several studies have shown that in-vehicle $\mathrm{PM}_{2.5}$ exposures can be higher than the near-roadway exposures in some circumstances [64, 65].

\section{Modifying effect estimates for $\mathrm{PM}_{2.5}$ of outdoor origin}

Data from the 1992-1994 National Human Activity Pattern Survey (NHAPS) showed that, on average, people in the US spent $68.7 \%$ of their time in residences, $18.2 \%$ of their time in indoor locations other than residences (e.g., offices, factories, bars, schools, and restaurants), 5.5\% of their time in vehicles, and $7.6 \%$ of their time outdoors [17]. Therefore, historically observed associations between outdoor $\mathrm{PM}_{2.5}$ concentrations and adverse health outcomes can reasonably be expected to have indirectly accounted for the underlying exposures to $\mathrm{PM}_{2.5}$ of outdoor origin that infiltrates and persists in these various microenvironments [66]. Failing to account for these underlying exposures to $\mathrm{PM}_{2.5}$ of outdoor origin in different microenvironments can lead to exposure misclassification and errors in effect estimates [35, 67-80]. To account for this phenomenon, we developed a modified mortality effect estimate for $\mathrm{PM}_{2.5}$ of outdoor origin (i.e.,

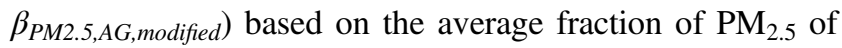
outdoor origin that infiltrates and persists in each assumed microenvironment (i.e., the infiltration factor) combined with the average fraction of time spent in each microenvironment, as shown in Eq. 4.

$\beta_{P M 2.5, A G, \text { modified }}=\frac{\beta_{P M 2.5}}{\Sigma F_{j} t_{j}}$

where $\beta_{P M 2.5}$ is the mortality effect estimate for outdoor $\mathrm{PM}_{2.5}$ from epidemiology studies that used outdoor concentrations as surrogates for average population exposure to outdoor $\mathrm{PM}_{2.5}, F_{j}$ is the average $\mathrm{PM}_{2.5}$ infiltration factor for microenvironment $j$, and $t_{j}$ is the fraction of time spent in each microenvironment $j . \Sigma F_{j} \times t_{j}$ is estimated using Eq. 5, which represents a weighted average of the product of the infiltration factors and fractional time spent in each of 
the four microenvironments used herein.

$$
\begin{array}{r}
\Sigma F_{j} \times t_{j}=(F \times t)_{\text {outdoor }}+(F \times t)_{\text {residence }}+(F \times t)_{\text {vehicle }} \\
+(F \times t)_{\text {other indoor }}
\end{array}
$$

We estimate a mean value of $\Sigma F_{j} \times t_{j}$ to be $\sim 0.60$ for the US population using a number of data sources as described in the SI. Although there would be variability in this value for each individual in a particular population included in a cohort study, this value is assumed to be broadly applicable as a reasonable estimate of the population-average value.

\section{Applying the model framework: scenario analyses}

We apply the model framework using MATLAB to estimate the magnitude and bounds of the US mortality burden of long-term average total $\mathrm{PM}_{2.5}$ exposures that result from indoor and outdoor PM sources in all non-smoking microenvironments. We define two primary scenarios that involve different assumptions and data sources for key input parameters, including: (i) a nationwide estimate based primarily on data from field measurements (where possible) and nationwide distributions of model input parameters; and (ii) a nationwide estimate based primarily on regionally varying modeled microenvironmental $\mathrm{PM}_{2.5}$ concentrations and other regionally varying model input parameters (where possible). A third scenario involves an application of the GBD IER model for comparison purposes; methods and results are included in the SI (although we have limited confidence in the approach for a number of reasons as described in the SI). Each model scenario is constructed to yield insight into how the framework can be used to generate mortality estimates and attribute them to microenvironmental exposures, while also highlighting unique data limitations present within each set of scenario assumptions.

For both Scenario 1 and 2, we use a central pooled estimate of RR for the increase in long-term all-cause mortality associated with outdoor $\mathrm{PM}_{2.5}$ concentrations in the US of $7.3 \%$ per $10 \mu \mathrm{g} / \mathrm{m}^{3}$ (95\% CI: $\left.3.7-11 \%\right)$ as reported in a recent quantitative meta-analysis of outdoor $\mathrm{PM}_{2.5} \mathrm{C}-\mathrm{R}$ functions [39]. We convert the pooled RR estimate of 1.073 per $10 \mu \mathrm{g} / \mathrm{m}^{3}$ to an effect estimate (i.e., $\beta_{P M 2.5}$ ) of 0.0070 (95\% CI: $\left.0.0036-0.0104\right)$, where $\beta_{P M 2.5}=$ $\ln (\mathrm{RR}) / 10$ [81]. We fit a Weibull distribution to these reported values, resulting in a mean $( \pm \mathrm{SD})$ value of $\beta_{P M 2.5}$ $=0.0070( \pm 0.0016)$ per $\mu \mathrm{g} / \mathrm{m}^{3}$ with distribution shape factors of $\alpha=0.765$ and $\beta=4.95$. A Weibull distribution was used because it yields a distribution that is very close to normal in shape, but does not produce any negative values. Moreover, we estimate $\beta_{P M 2.5, A G \text {,modified }}$ to be $\sim 0.0117$ per $\mu \mathrm{g} / \mathrm{m}^{3}$ using Eq. 4 (i.e., 0.0070 divided by 0.6 ) with a $95 \%$
CI of $0.0060-0.0174$ per $\mu \mathrm{g} / \mathrm{m}^{3}$. This modified effect estimate for all-cause mortality associated with outdoor $\mathrm{PM}_{2.5}$ represents a more generalizable effect estimate that accounts for the population-average locations and durations in which people are likely exposed to $\mathrm{PM}_{2.5}$ of outdoor origin.

\section{Scenario 1: Nationwide estimate based primarily on prior field studies}

In Scenario 1, we estimated the mortality burden for the adult population 35 years and older using nationwide distributions of model inputs. We assumed a national annual average outdoor $\mathrm{PM}_{2.5}$ concentration of $9.1 \mu \mathrm{g} / \mathrm{m}^{3}$ with 10 th and 90th percentiles of 6.6 and $11.2 \mu \mathrm{g} / \mathrm{m}^{3}$, respectively, taken from the EPA's nationwide monitoring network data for the year 2012 [82]. The year 2012 was chosen because it was the year for which we had the most comprehensive national (Scenario 1) and regional (Scenario 2) estimates for indoor and outdoor $\mathrm{PM}_{2.5}$ concentrations. We fit a $\log$ normal distribution through the reported arithmetic mean and percentiles to construct a distribution from which to sample $\left(\mathrm{GM}=8.84 \mu \mathrm{g} / \mathrm{m}^{3}\right.$ and $\left.\mathrm{GSD}=1.246\right)$. We assumed a baseline (i.e., threshold) $\mathrm{PM}_{2.5}$ concentration of zero in each microenvironment, which is consistent with other recent applications of the core health impact function used in this scenario [42, 43] and with a number of studies that suggest there is no evidence of a population threshold in the relationship between long-term exposure to ambient $\mathrm{PM}_{2.5}$ and mortality [83-86]. We assumed that the 2012 nationwide population (Pop) and mortality rate $\left(y_{0}\right)$ for persons 35 years and older were $166,516,716$ and $1.463 \times 10^{-2}$ per person per year, respectively, using data from the CDC WONDER system [87].

We used Monte Carlo simulations with 10,000 iterations to sample from what we assumed for the purposes of Scenario 1 to be nationally representative distributions of every other model input parameter, including modified $\mathrm{PM}_{2.5}$ mortality effect estimates (described previously), timeactivity patterns, and estimates of long-term average $\mathrm{PM}_{2.5}$ concentrations of both indoor and outdoor origin in each microenvironment taken largely from prior field measurements. There are three versions of Scenario 1, each of which involved sampling from different distributions to estimate residential $\mathrm{PM}_{2.5}$ concentrations of both indoor and outdoor origin. We sampled data from (i) the Relationship of Indoor, Outdoor and Personal Air (RIOPA) [13] and (ii) the Multi-Ethnic Study of the Atherosclerosis and Air Pollution (MESA Air) [18, 19] studies independently, as well as (iii) both RIOPA and MESA equally. Briefly, the RIOPA study measured indoor and outdoor $\mathrm{PM}_{2.5}$ concentrations concurrently for $48 \mathrm{~h}$ in 212 non-smoking residences in three US cities, while MESA Air measured indoor 
and outdoor $\mathrm{PM}_{2.5}$ concentrations concurrently over a 2week period in 208 homes in warm seasons and 264 homes in cold seasons in seven US cities. Crucially, subsequent analyses of both data sets reported distributions of $\mathrm{PM}_{2.5}$ infiltration factors, which can be used to estimate the relative contributions of both indoor and outdoor sources to indoor $\mathrm{PM}_{2.5}$ concentrations in the sample residences. Although a few other studies have also explicitly measured indoor concentrations of $\mathrm{PM}_{2.5}$ in US residences resulting from indoor and outdoor sources, including a study of 294 inner-city homes of children with asthma in seven cities [27] and 68 smoking and non-smoking homes in six cities [88], we chose to rely on the RIOPA and MESA Air studies because they included large sample sizes of non-smoking homes occupied by adults in multiple US cities.

All relevant model inputs and data sources for Scenario 1 are summarized in full in the SI. Each model iteration represents a population-level estimate of total mortality summed across all microenvironmental exposures; thus, the central tendency of the model output provides the most likely estimate of the magnitude of the total mortality associated with $\mathrm{PM}_{2.5}$ exposure and the output range informs the likely bounds of that estimate. In all microenvironments, if a sampled value of a microenvironmental $\mathrm{PM}_{2.5}$ concentration was a negative value, it was replaced with zero.

\section{Scenario 2: Nationwide estimate based on regional model outputs}

In Scenario 2, we similarly applied the model framework to make a nationwide estimate of the total mortality burden attributable to microenvironmental $\mathrm{PM}_{2.5}$ exposures, albeit using regional assumptions for some input parameters for which regional data were available, including population demographics, baseline over-35 adult mortality rates, outdoor $\mathrm{PM}_{2.5}$ concentrations, and, importantly, residential indoor $\mathrm{PM}_{2.5}$ concentrations of both indoor and outdoor origin. We used the same nationwide distributions of timeactivity patterns and all non-residential indoor microenvironmental $\mathrm{PM}_{2.5}$ concentrations from Scenario 1 because we are not aware of any robust regional data sets for these parameters. However, given that the Scenario 1 analysis demonstrated the sensitivity of the model to assumptions for residential exposures, and given that other air pollution risk assessments have shown the utility of using geographically varying population demographics and mortality rates [38, 42], we consider Scenario 2 a reasonable, albeit somewhat limited, attempt to construct a national mortality estimate using more granular input data.

Scenario 2 uses regional estimates of residential indoor $\mathrm{PM}_{2.5}$ concentrations of indoor origin and ambient infiltration factors recently made using a nationally representative set of combined residential energy and indoor air quality (REIAQ) models for non-smoking US residences [89]. Briefly, the REIAQ model set combined building energy models with dynamic pollutant mass balance models to estimate the hourly concentrations of a number of pollutants of indoor and outdoor origin, including $\mathrm{PM}_{2.5}$, in a total of 3971 individual home models in 19 cities that are estimated to represent $\sim 80 \%$ of the US housing stock as of approximately the early 2000s. The model set assumed cooking was the primary indoor $\mathrm{PM}_{2.5}$ source and assumed the same generation rates and cooking frequency for all homes. The model set also accounted for historical outdoor $\mathrm{PM}_{2.5}$ concentrations and modeled infiltration air exchange rates, window opening behaviors, and forced air heating and cooling system runtimes based on historical outdoor environmental conditions combined with a building physics model. We used these modeled results for the regionally varying annual average residential indoor $\mathrm{PM}_{2.5}$ concentrations of indoor origin (i.e., $\Delta C_{P M 2.5, \text { IG, residences }}$ ) in conjunction with regional distributions of ambient $\mathrm{PM}_{2.5}$ infiltration factors combined with regional distributions of outdoor $\mathrm{PM}_{2.5}$ concentrations for the year 2012 from EPA [82] to generate estimates of $\Delta C_{P M 2.5, A G \text {,residences }}$ in each of the 19 modeled cities. We used the infiltration factor approach (rather than using values of $\Delta C_{P M 2.5, A G \text {,residences }}$ directly from REIAQ) because the model set is weighted more heavily toward homes in cities with higher ambient $\mathrm{PM}_{2.5}$ concentrations than rural areas, while the EPA outdoor concentration data are more broadly applicable to the rest of the population.

We grouped the REIAQ model outputs for each of the 3971 home models into nine US census divisions and calculated a population-weighted annual average and SD for $\Delta C_{P M 2.5, I G, \text { residences }}$ and infiltration factors $\left(F_{\text {inf }}\right)$ across all homes in each division (Table 1). We fit beta and lognormal distributions to summary statistics of infiltration factors and indoor $\mathrm{PM}_{2.5}$ concentration of indoor origin, respectively, for Monte Carlo sampling from each division. For $\mathrm{PM}_{2.5}$ of ambient origin, we used annual average (and 10th and 90th percentiles) outdoor $\mathrm{PM}_{2.5}$ concentration data for nine US regions reported by EPA [82]. Because the nine EPA regions group states differently than the nine US census divisions, we regrouped the EPA data by assuming that every state in an EPA region had the same annual outdoor $\mathrm{PM}_{2.5}$ concentration summary statistics as other states in that region. We estimated the annual average (and 10th and 90th percentile) outdoor $\mathrm{PM}_{2.5}$ concentration in each census division by weighting each assumed state-level summary statistic by the population in each census division. We fit lognormal distributions to the resulting estimates of annual outdoor $\mathrm{PM}_{2.5}$ summary statistics (means and 10th and 90th percentiles) in each division for subsequent Monte Carlo sampling. 
We then ran the 10,000 iteration Monte Carlo analysis 9 times-one for each census division-with over-35 adult mortality rates and populations [87] (also shown in Table 1) to yield estimates of total mortality and distributions of the different microenvironmental exposure contributions in each division. We summed the median total mortality estimates from each census division to generate an estimate of the national mortality burden associated with total $\mathrm{PM}_{2.5}$ exposure. We estimated the mortality burden attributable to each microenvironment and source type using the average fractional exposure contributions multiplied by the best estimate (i.e., median) total mortality, similar to Scenario 1.

\section{Results and Discussion}

\section{Scenario 1: Nationwide estimates based primarily on prior field studies}

The resulting distributions of estimates of the annual US mortality burden of total $\mathrm{PM}_{2.5}$ exposure in 2012 attributable to both indoor and outdoor sources in all microenvironments combined using assumptions in Scenario 1 are shown in Fig. 1. Results for all three RIOPA and MESA sampling approaches were approximately lognormally distributed with a Shapiro-Wilk test statistic $(W)>0.98$ and $p$ $<0.00001$ on the log-transformed values for each case. We consider the median values as our most likely estimate of the total mortality burden of all $\mathrm{PM}_{2.5}$ exposures for each scenario, with an interquartile range (IQR, or 25 th to 75 th percentiles) serving as a measure of the most reasonable bounds of the central estimate. The median (IQR) estimate of the total mortality associated with all $\mathrm{PM}_{2.5}$ exposures for each scenario were $298,200(198,600-479,500), \sim 229,400$ $(171,400-306,700)$, and $\sim 255,800 \quad(180,600-380,700)$ deaths for the $100 \%$ RIOPA, $100 \%$ MESA, and 50\%/50\% RIOPA/MESA scenarios, respectively. These estimates would mean that aggregate $\mathrm{PM}_{2.5}$ exposures accounted for between 9 and $12 \%$ of the total number of adult deaths over the age of 35 in 2012.

Distributions of the estimated fractional exposure contributions from indoor and outdoor sources in each microenvironment modeled in Scenario 1 are shown in Fig. 2. In each of the three RIOPA/MESA cases, residential $\mathrm{PM}_{2.5}$ exposure to indoor and outdoor sources combined was the dominant exposure, accounting for $70 \%$ of the total $\mathrm{PM}_{2.5}$ exposure across all three scenarios, on average. Residential exposure accounted for an average of $\sim 67 \%$ of the total exposure to $\mathrm{PM}_{2.5}$ of outdoor origin across the three scenarios, followed by an average of $\sim 17 \%$ of outdoor origin exposure attributed to other indoor environments, with direct outdoor exposure accounting for only $\sim 12 \%$ of all outdoor-origin exposure, on average.

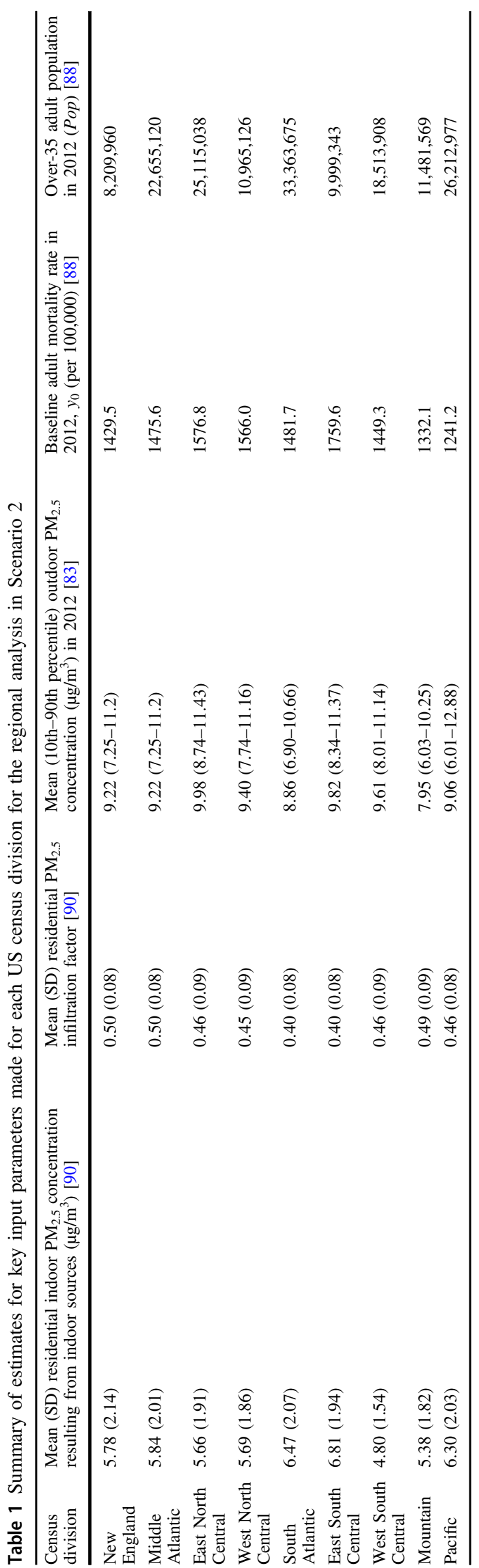



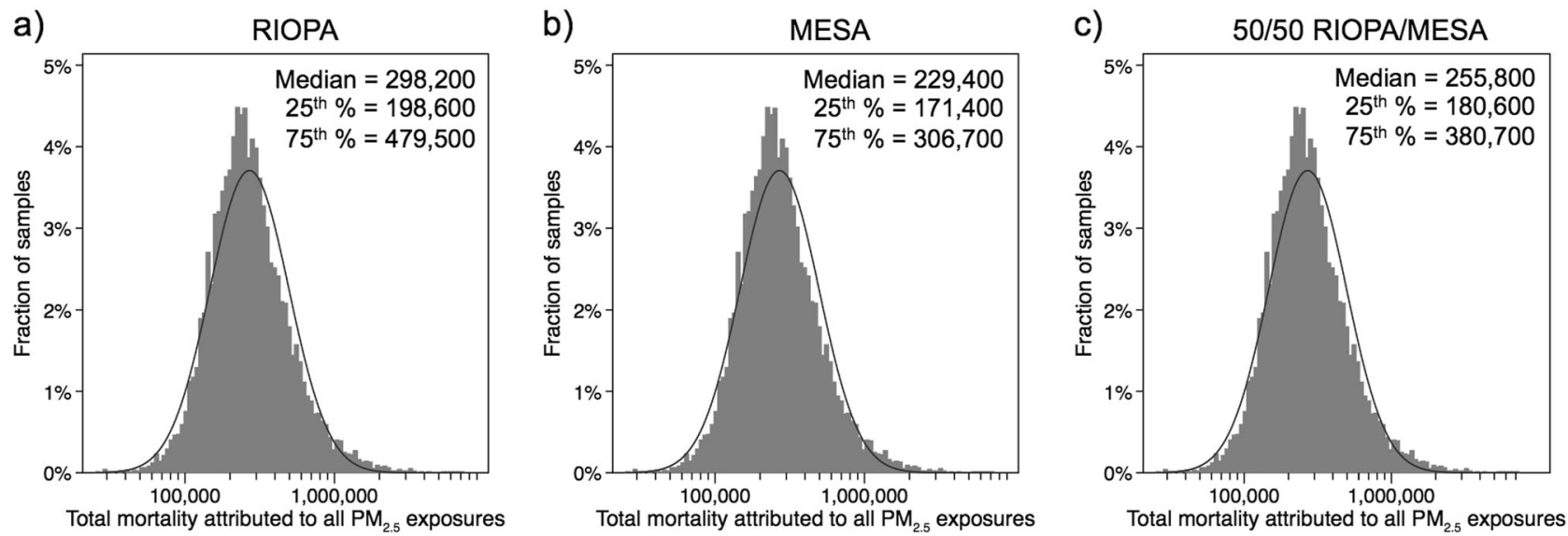

Fig. 1 Frequency distributions of the total annual US $\mathrm{PM}_{2.5}$ mortality burden estimated by Monte Carlo simulations of microenvironmental exposures to $\mathrm{PM}_{2.5}$ of both indoor and outdoor origin using three cases

from: a RIOPA-only, b MESA-only, and $\mathbf{c}$ from RIOPA and MESA equally (i.e., 50/50 RIOPA/MESA). The approximate curve fit is a lognormal distribution and summary statistics (median and interin Scenario 1, including sampling residential indoor concentrations

a)

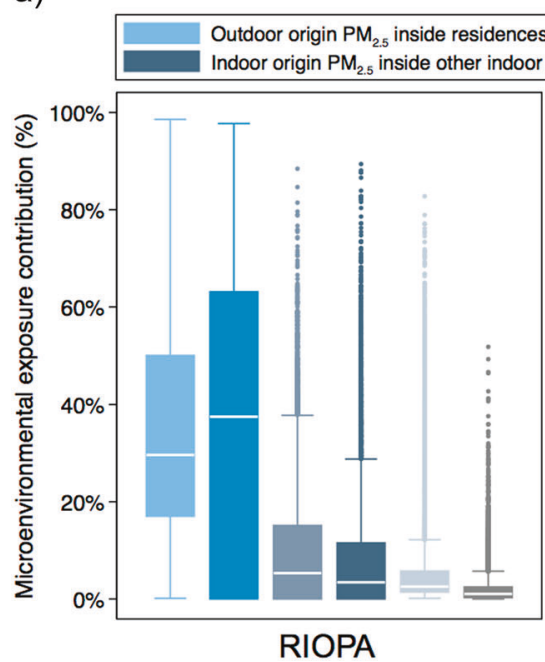

Fig. 2 Distributions of the estimated contributions of microenvironmental exposures to $\mathrm{PM}_{2.5}$ of indoor and outdoor origin to total $\mathrm{PM}_{2.5}$ exposures across the US population using the three Scenario 1 cases: sampling residential indoor concentrations from a RIOPA-only, b MESA only, and c RIOPA and MESA equally (i.e., 50/50 RIOPA/

In both the MESA-only and the combined RIOPA/ MESA 50/50 scenarios, residential exposure to $\mathrm{PM}_{2.5}$ of outdoor origin dominated total exposure, accounting for an average of 48 and $42 \%$ of total exposure in the MESAonly and 50/50 combined scenarios, respectively. Residential exposure to $\mathrm{PM}_{2.5}$ of indoor origin was the second largest contributor to total exposure in these two scenarios, ranging from an average of 19 to $28 \%$ of total exposure in the MESA-only and 50/50 combined scenarios, respectively. Conversely, the largest contributor to total exposure in the RIOPA-only scenario was residential exposure to $\mathrm{PM}_{2.5}$ of indoor origin (average of $37 \%$ ) followed by c)

Outdoor origin $\mathrm{PM}_{2.5}$ inside other indoor locations Outdoor origin $\mathrm{PM}_{2.5}$ inside vehicles

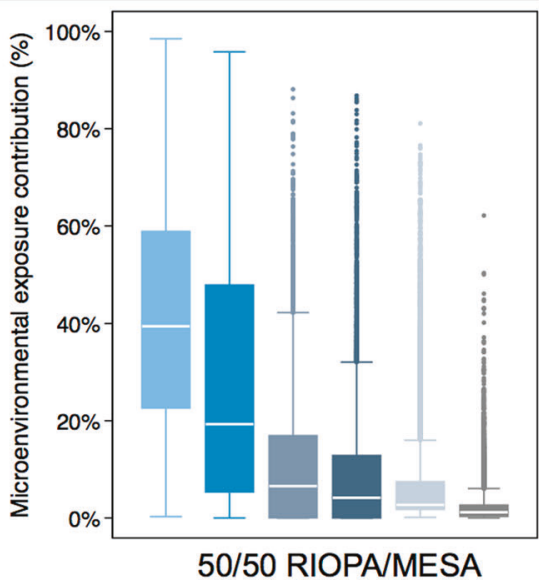

50/50 RIOPA/MESA

MESA

MESA). Boxes represent 25th and 75th percentile values (i.e., interquartile range, or IQR); horizontal line represents median values; whiskers represent upper and lower adjacent values (i.e., $50 \%$ beyond the IQR)

residential exposure to $\mathrm{PM}_{2.5}$ of outdoor origin (average of $36 \%$ ). Given the wide ranges of exposure contributions generated by sampling from RIOPA and MESA separately, and given the large differences in the two study designs and findings, we expect the combined 50/50 RIOPA/MESA sampling approach to yield the most plausible nationwide exposure estimates of the three approaches in Scenario 1. Thus, we use only the combined 50/50 RIOPA/MESA study results from Figs. 1 and 2 to estimate the likely mortality burden associated with microenvironmental exposure to $\mathrm{PM}_{2.5}$ of indoor and outdoor origin in Scenario 1 (Table 2). 
Table 2 Mean, standard deviation (SD), and interquartile range (IQR: 25 th to 75 th percentiles) of the estimated contributions of indoor and outdoor sources in each microenvironment to total $\mathrm{PM}_{2.5}$ exposures and the estimated associated US mortality burden in Scenario 1 (50/50 RIOPA/MESA)

\begin{tabular}{|c|c|c|c|}
\hline $\begin{array}{l}\text { Outdoor or } \\
\text { indoor } \\
\text { sources }\end{array}$ & Microenvironment & $\begin{array}{l}\text { Mean fraction } \\
\text { of total } \mathrm{PM}_{2.5} \\
\text { exposure } \pm \\
\text { SD [IQR] }\end{array}$ & $\begin{array}{l}\text { Mean estimate of } \\
\text { annual deaths } \\
\text { attributed to total } \\
\mathrm{PM}_{2.5} \text { exposure } \pm \\
\text { SD [IQR] }\end{array}$ \\
\hline \multirow{8}{*}{$\begin{array}{l}\text { Due to } \\
\mathrm{PM}_{2.5} \text { of } \\
\text { outdoor } \\
\text { origin }\end{array}$} & \multirow[t]{2}{*}{ Residences } & $42.1 \pm 23.8 \%$ & $107,700 \pm 61,000$ \\
\hline & & [22.6-58.9\%] & {$[57,800-150,600]$} \\
\hline & \multirow{2}{*}{$\begin{array}{l}\text { Other indoor } \\
\text { locations }\end{array}$} & $10.9 \pm 12.9 \%$ & $28,000 \pm 33,000$ \\
\hline & & {$[0-16.9 \%]$} & {$[100-43,300]$} \\
\hline & \multirow[t]{2}{*}{ Vehicles } & $2.4 \pm 3.9 \%$ & $6100 \pm 9900$ \\
\hline & & {$[0.3-2.6 \%]$} & [900-6700] \\
\hline & \multirow[t]{3}{*}{ Outdoor } & $7.3 \pm 11.1 \%$ & $18,800 \pm 28,600$ \\
\hline & & {$[1.8-7.5 \%]$} & {$[4,500-19,100]$} \\
\hline $\begin{array}{l}\text { Total } \\
\text { outdoor } \\
\text { contribution }\end{array}$ & & $62.7 \pm 25.2 \%$ & $\begin{array}{l}160,500 \pm 40,400 \\
{[63,300-219,600]}\end{array}$ \\
\hline \multirow{6}{*}{$\begin{array}{l}\text { Due to } \\
\mathrm{PM}_{2.5} \text { of } \\
\text { indoor } \\
\text { origin }\end{array}$} & Residences & $\begin{array}{l}28.1 \pm 26.3 \% \\
{[5.3-47.9 \%]}\end{array}$ & $\begin{array}{l}72,000 \pm 67,300 \\
{[13,700-122,600]}\end{array}$ \\
\hline & $\begin{array}{l}\text { Other indoor } \\
\text { locations }\end{array}$ & $\begin{array}{l}9.1 \pm 12.6 \% \\
{[0-12.8 \%]}\end{array}$ & $\begin{array}{l}23,300 \pm 32,200 \\
{[0-32,800]}\end{array}$ \\
\hline & \multirow[t]{2}{*}{ Vehicles } & $\mathrm{n} / \mathrm{a}$ & $\mathrm{n} / \mathrm{a}$ \\
\hline & & $\mathrm{n} / \mathrm{a}$ & $\mathrm{n} / \mathrm{a}$ \\
\hline & \multirow[t]{2}{*}{ Outdoor } & $\mathrm{n} / \mathrm{a}$ & $\mathrm{n} / \mathrm{a}$ \\
\hline & & $\mathrm{n} / \mathrm{a}$ & $\mathrm{n} / \mathrm{a}$ \\
\hline $\begin{array}{l}\text { Total indoor } \\
\text { contribution }\end{array}$ & & $37.3 \pm 25.2 \%$ & $\begin{array}{l}95,300 \pm 24,000 \\
{[13,700-155,400]}\end{array}$ \\
\hline $\begin{array}{l}\text { Total } \\
\text { contribution }\end{array}$ & & $100 \%$ & {$[77,000-375,000]$} \\
\hline
\end{tabular}

Mortality burden estimates are based on the 'best estimate' of the median total mortality burden resulting from Monte Carlo sampling of the RIOPA and MESA studies combined (i.e., each sampled equally: 50/50 RIOPA/MESA)

We estimate the mortality burden associated with $\mathrm{PM}_{2.5}$ exposure in each microenvironment by multiplying the mean fractional exposure contribution (from Fig. 2) by the median total mortality burden of $\sim 255,800$ deaths per year for the combined 50/50 RIOPA/MESA scenario (from Fig. 1). Using this approach, we estimate that exposure to $\mathrm{PM}_{2.5}$ of outdoor origin across all microenvironments accounted for $\sim 160,500$ deaths in 2012 (IQR of $\sim 63,300$ to $\sim 219,600$ deaths), while exposure to $\mathrm{PM}_{2.5}$ of indoor origin across all microenvironments accounted for $\sim 95,300$ deaths (IQR of $\sim 13,700$ to $\sim 155,400$ ). Our estimate of the mortality burden attributable to outdoor sources is between the $\sim 120,000$ and $\sim 200,000$ deaths in 2010 estimated by Fann et al. (2017) [42] using RR estimates and response functions from Krewski et al. (2009) [5] and Nasari et al. (2016) [45], respectively. However, our estimate is almost twice the 88,400 deaths in 2015 estimated by Cohen et al. (2017) [55] largely because of the threshold concentration used (i.e., zero compared to a uniform distribution between 2.4 and $5.8 \mu \mathrm{g} / \mathrm{m}^{3}$ ) and also because of the use of a different model form and associated effect estimates that are not modified to account for microenvironmental exposure to outdoor-origin $\mathrm{PM}_{2.5}$. Both issues are explored in more detail in Scenario 3 in the SI.

In the combined 50/50 RIOPA/MESA scenario, we estimate that the largest contributor to $\mathrm{PM}_{2.5}$-associated mortality is residential indoor exposure to $\mathrm{PM}_{2.5}$ of outdoor origin, accounting for an estimated $\sim 107,700$ deaths annually (IQR of $\sim 57,800$ to $\sim 150,600$ ). The next largest contributor is residential indoor exposure to $\mathrm{PM}_{2.5}$ of indoor origin, accounting for an estimated $\sim 72,000$ deaths annually (IQR of $\sim 13,700$ to $\sim 122,600$ ). Indoor exposure to $\mathrm{PM}_{2.5}$ of indoor and outdoor origin in other indoor locations is estimated to account for $\sim 23,300$ (IQR of $\sim 0$ to $\sim 32,800$ ) and $\sim 28,000$ (IQR of $\sim 100$ to $\sim 43,300$ ) deaths annually, respectively. Finally, outdoor exposure to $\mathrm{PM}_{2.5}$ of outdoor origin is estimated to account for only $\sim 18,800$ (IQR of $\sim 4,500$ to $\sim 19,100$ ) deaths annually. Overall, these results demonstrate the importance of indoor environments, and particularly residential indoor environments, in governing human exposure to $\mathrm{PM}_{2.5}$ of both indoor and outdoor origin, and provide novel estimates of the potential magnitude of the nationwide mortality burden associated with these exposures.

\section{Scenario 2: Nationwide estimate based on regional model outputs}

Table 3 shows estimates of regional and total mortality associated with microenvironmental $\mathrm{PM}_{2.5}$ exposures resulting from the regional model application (Scenario 2). The median (IQR) estimate of the total mortality associated with all $\mathrm{PM}_{2.5}$ exposures across all microenvironments and sources was 281,800 (159,700-359,300), which places Scenario 2 approximately between the RIOPA-only and 50/ 50 RIOPA/MESA cases from Scenario 1. Exposure to $\mathrm{PM}_{2.5}$ of outdoor and indoor origin in all microenvironments was estimated to account for $\sim 139,500$ deaths (IQR of $\sim 69,600$ to $\sim 177,900$ ) and $\sim 142,300$ deaths (IQR of $\sim 90,100$ to $\sim 181,400$ ) in 2012 , respectively. The relative contributions of indoor and outdoor $\mathrm{PM}_{2.5}$ sources to total mortality are approximately equal, largely because of the use of relatively high indoor concentrations (similar to the RIOPA-only approach in Scenario 1) and relatively low residential infiltration factors that were estimated in the REIAQ model set. Accordingly, residential indoor $\mathrm{PM}_{2.5}$ of indoor origin is estimated to be the single dominant 
Table 3 Estimates of regional and total mortality associated with microenvironmental exposures to $\mathrm{PM}_{2.5}$ of indoor and outdoor origin in 2012 resulting from the regional Monte Carlo procedure (Scenario 2)

\begin{tabular}{|c|c|c|c|c|c|c|c|c|c|c|}
\hline \multirow[t]{2}{*}{ Census division } & \multirow[t]{2}{*}{ Percentile } & \multirow[t]{2}{*}{$\begin{array}{l}\text { Total } \\
\text { mortality }\end{array}$} & \multicolumn{5}{|c|}{ Mortality associated with $\mathrm{PM}_{2.5}$ of ambient origin } & \multicolumn{3}{|c|}{$\begin{array}{l}\text { Mortality associated with } \mathrm{PM}_{2.5} \text { of } \\
\text { indoor origin }\end{array}$} \\
\hline & & & $\begin{array}{l}\text { Inside } \\
\text { residences }\end{array}$ & $\begin{array}{l}\text { Other } \\
\text { indoors }\end{array}$ & Vehicles & Outdoor & Total & $\begin{array}{l}\text { Inside } \\
\text { residences }\end{array}$ & $\begin{array}{l}\text { Other } \\
\text { indoors }\end{array}$ & Total \\
\hline \multirow[t]{3}{*}{ New England } & Median & 13,900 & 4500 & 1400 & 300 & 1000 & 7200 & 5500 & 1200 & 6700 \\
\hline & 25 th $\%$ & 7900 & 3400 & 0 & 100 & 200 & 3700 & 4200 & 0 & 4200 \\
\hline & 75 th $\%$ & 17,600 & 5600 & 2200 & 300 & 1000 & 9100 & 6900 & 1600 & 8600 \\
\hline \multirow[t]{3}{*}{ Middle Atlantic } & Median & 39,600 & 12,800 & 4100 & 900 & 2600 & 20,400 & 15,900 & 3300 & 19,300 \\
\hline & 25 th $\%$ & 22,700 & 9800 & 0 & 100 & 700 & 10,600 & 12,200 & 0 & 12,200 \\
\hline & 75th $\%$ & 50,300 & 15,800 & 6300 & 1000 & 2600 & 25,700 & 19,900 & 4600 & 24,500 \\
\hline \multirow{3}{*}{$\begin{array}{l}\text { East North } \\
\text { Central }\end{array}$} & Median & 47,100 & 15,100 & 5200 & 1100 & 3300 & 24,800 & 18,300 & 4000 & 22,300 \\
\hline & 25 th $\%$ & 26,200 & 11,300 & 0 & 200 & 900 & 12,500 & 13,800 & 0 & 13,800 \\
\hline & 75 th $\%$ & 60,200 & 18,800 & 8200 & 1200 & 3400 & 31,700 & 23,000 & 5500 & 28,500 \\
\hline \multirow{3}{*}{$\begin{array}{l}\text { West North } \\
\text { Central }\end{array}$} & Median & 19,700 & 6100 & 2100 & 400 & 1300 & 9900 & 8100 & 1700 & 9800 \\
\hline & 25 th $\%$ & 11,100 & 4600 & 0 & 100 & 400 & 5000 & 6100 & 0 & 6100 \\
\hline & 75 th $\%$ & 25,100 & 7500 & 3300 & 500 & 1300 & 12,600 & 10,100 & 2400 & 12,500 \\
\hline \multirow[t]{3}{*}{ South Atlantic } & Median & 56,200 & 14,600 & 5700 & 1200 & 3700 & 25,300 & 26,100 & 4800 & 30,900 \\
\hline & 25 th $\%$ & 32,400 & 10,800 & 0 & 200 & 1000 & 12,000 & 20,400 & 0 & 20,400 \\
\hline & 75th $\%$ & 71,600 & 18,200 & 9000 & 1400 & 3800 & 32,500 & 32,400 & 6700 & 39,200 \\
\hline \multirow{3}{*}{$\begin{array}{l}\text { East South } \\
\text { Central }\end{array}$} & Median & 21,600 & 5800 & 2300 & 500 & 1500 & 10,000 & 9800 & 1800 & 11,600 \\
\hline & 25 th $\%$ & 12,500 & 4400 & 0 & 100 & 400 & 4900 & 7700 & 0 & 7700 \\
\hline & 75th $\%$ & 27,500 & 7100 & 3700 & 600 & 1500 & 12,800 & 12,100 & 2500 & 14,600 \\
\hline \multirow{3}{*}{$\begin{array}{l}\text { West South } \\
\text { Central }\end{array}$} & Median & 29,300 & 9800 & 3300 & 700 & 2100 & 16,000 & 10,600 & 2700 & 13,300 \\
\hline & 25 th $\%$ & 15,800 & 7300 & 0 & 100 & 600 & 8000 & 7800 & 0 & 7800 \\
\hline & 75th $\%$ & 37,700 & 12,400 & 5300 & 800 & 2200 & 20,600 & 13,400 & 3700 & 17,100 \\
\hline \multirow[t]{3}{*}{ Mountain } & Median & 16,000 & 4800 & 1600 & 300 & 1000 & 7800 & 6700 & 1500 & 8200 \\
\hline & 25 th $\%$ & 9000 & 3700 & 0 & 100 & 300 & 4000 & 5100 & 0 & 5100 \\
\hline & 75 th $\%$ & 20,400 & 6000 & 2500 & 400 & 1000 & 9800 & 8400 & 2100 & 10,500 \\
\hline \multirow[t]{3}{*}{ Pacific } & Median & 38,500 & 11,100 & 3800 & 800 & 2500 & 18,200 & 17,000 & 3300 & 20,300 \\
\hline & 25 th $\%$ & 22,000 & 8300 & 0 & 100 & 600 & 9000 & 13,000 & 0 & 13,000 \\
\hline & 75 th $\%$ & 48,900 & 13,800 & 5900 & 900 & 2400 & 23,000 & 21,300 & 4600 & 25,900 \\
\hline \multirow[t]{3}{*}{ Total } & Median & 281,800 & 84,700 & 29,500 & 6200 & 19,100 & 139,500 & 118,000 & 24,400 & 142,300 \\
\hline & 25 th $\%$ & 159,700 & 63,500 & 0 & 1100 & 5000 & 69,600 & 90,100 & 0 & 90,100 \\
\hline & 75 th $\%$ & 359,300 & 105,200 & 46,400 & 7100 & 19,200 & 177,900 & 147,600 & 33,800 & 181,400 \\
\hline
\end{tabular}

contributor to the total mortality burden in Scenario 2, followed by residential indoor $\mathrm{PM}_{2.5}$ of outdoor origin.

Total mortality in Scenario 2 is driven largely by $\mathrm{PM}_{2.5}$ exposures in the most populated census divisions: South Atlantic, East North Central, Middle Atlantic, and Pacific. The East South Central census division had the highest estimated mortality associated with $\mathrm{PM}_{2.5}$ per capita because of relatively high residential indoor concentrations resulting form indoor sources combined with the highest baseline adult mortality rate in 2012. The lowest per capita mortality estimate was in the Mountain census division, with moderate residential indoor $\mathrm{PM}_{2.5}$ concentrations and a moderate baseline mortality rate. Regional differences in $\Delta C_{P M 2.5, I G, \text { residences }}$ were driven variations in air exchange rates [89] and system runtimes (which primarily affects particle filtration [90]).

Best estimates of the total mortality burden associated with $\mathrm{PM}_{2.5}$ exposure in the US made using the assumptions in Scenarios 1 and 2, as well as the contribution of each microenvironmental and source-specific exposure, are shown in Fig. 3 for direct comparison. Although the magnitude of total mortality varies in each scenario, best estimates consistently range from $\sim 230,000$ to $\sim 300,000$ deaths in 2012. Residential exposures to $\mathrm{PM}_{2.5}$ from indoor sources drive the vast majority of variability in each case, suggesting that a better understanding of the nationwide contribution of indoor sources to total exposure are needed, as is a better understanding of the toxicity of indoor sources. 


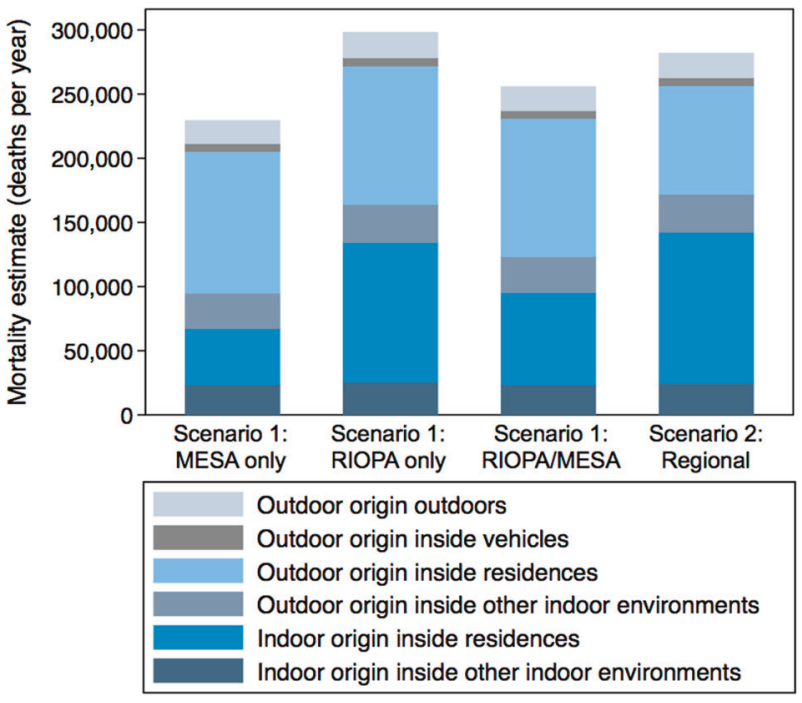

Fig. 3 Best estimates of the number of annual deaths in the US associated with exposure to $\mathrm{PM}_{2.5}$ of indoor and outdoor origin in each microenvironment in Scenarios 1 and 2

\section{Limitations}

One obvious assumption in this work is that the observed relationships between outdoor $\mathrm{PM}_{2.5}$ concentrations and mortality in the epidemiology literature are indeed causal and that the underlying exposure-response functions and effect estimates accurately reflect a causal and quantifiable relationship [91-94]. Further, the framework assumes that the exposure-response function in Eq. 1 (i) has no threshold $\mathrm{PM}_{2.5}$ concentration below which additional mortality does not occur [83-86] and (ii) appropriately describes the shape of the observed mortality responses from prior epidemiology studies [95]. Additionally, we do not make any modifications to the exposure-response function and effect estimates based on the magnitude of $\mathrm{PM}_{2.5}$ exposure concentrations or varying chemical constituents of $\mathrm{PM}_{2.5}$, although there is some evidence that both of these adjustments may be warranted [96-100]. Moreover, the framework assumes that there is no double counting of the health effects of indoor $\mathrm{PM}_{2.5}$ sources. We consider this a reasonable assumption because most studies have reported relatively low correlations between personal and ambient $\mathrm{PM}_{2.5}$ concentrations (i.e., $R^{2}<0.3$ ) [13, 69], but the potential for ambient $\mathrm{PM}_{2.5}$ mortality effect estimates resulting from epidemiology cohort studies including an inherent but un-quantified indoor contribution remains.

Another obvious assumption and potential limitation in this work is that we assume that the modified exposureresponse endpoint effect estimates for mortality associated with $\mathrm{PM}_{2.5}$ from both indoor and outdoor sources are the same, and that there are no changes in $\mathrm{PM}_{2.5}$ toxicity that occur due to size-resolved aerosol dynamics that govern the particle infiltration and persistence process. Although some studies have suggested that particles of outdoor origin may be more harmful than indoor-generated particles [59, 60], other studies have shown that indoor-generated fine particulate matter is at least as toxic as outdoor particulate matter [61], if not more [62]. However, there is a tremendous lack of data to support or reject either assumption at this time. Given the lack of data on mortality endpoints from various indoor and outdoor $\mathrm{PM}_{2.5}$ sources, we consider this a reasonable assumption for this exploratory analysis. This same assumption also has precedent in a number of other recent studies in the literature that have evaluated mortality endpoints associated with indoor and outdoor $\mathrm{PM}_{2.5}$ sources [46-48]. Additionally, there is mounting evidence from air filter intervention studies in homes that reducing indoor $\mathrm{PM}_{2.5}$ concentrations (comprising a mixture of both indoor and outdoor sources) can lead to improvements in some biomarkers and other clinical measures that are associated with both short-term and long-term cardiovascular health endpoints [101-107].

There are also several assumptions implicit in our approach to modifying health endpoint effect estimates $(\beta)$ to account for the underlying exposures to $\mathrm{PM}_{2.5}$ of outdoor origin that likely occurred in the original epidemiology populations from which effect estimates are derived. First, we assumed that the distributions of activity patterns and residential building characteristics (i.e., infiltration factors) that we used match both the general population and the epidemiology cohort populations, although this may not be true. For example, elderly populations who are more susceptible to adverse effects associated with $\mathrm{PM}_{2.5}$ exposure tend to spend more time indoors than the general population. Second, we did not consider some potential non-linear effects of various parameters including potential covariance of infiltration factors and ambient $\mathrm{PM}_{2.5}$ as well as occupancy and indoor particle generation. Third, we assumed that the human activity patterns reported in NHAPS [17] are still valid in 2012, even though data were collected in 1992-1994.

Despite the large uncertainties associated with this work, the exposure attribution and mortality burden estimates clearly demonstrate the importance of considering indoor microenvironments in $\mathrm{PM}_{2.5}$ exposure assessments and epidemiology studies. They also illustrate the potential magnitude and reasonable bounds of the mortality burden potentially associated with microenvironmental exposures to $\mathrm{PM}_{2.5}$ of both indoor and outdoor origin. Results also demonstrate that efforts to reduce the US $\mathrm{PM}_{2.5}$ associated mortality burden should at least consider indoor pollutant control in addition to controlling outdoor sources. This model framework can also be used for high-level policy analysis of the costs and benefits of reducing exposures to $\mathrm{PM}_{2.5}$ of indoor and outdoor origin 
through various interventions (e.g., source control, air purifiers, changing infiltration/ventilation across the building stock, etc.).

This work intentionally focuses solely on non-smoking homes; further model applications could include incorporating data on smoking rates and contributions to indoor $\mathrm{PM}_{2.5}$ concentrations. This work also highlights the need for several areas of research to improve these estimates and reduce uncertainty. For example, a better understanding of how outdoor $\mathrm{PM}_{2.5}$ infiltration factors vary geographically and by different building types is needed to more accurately characterize outdoor $\mathrm{PM}_{2.5}$ exposures for epidemiology studies. Additionally, a better understanding of the toxicity of both indoor and outdoor origin $\mathrm{PM}_{2.5}$ is needed, including characterizing the toxicity of a wide variety of typical indoor sources and also characterizing how the sizeresolved dynamics of the outdoor $\mathrm{PM}_{2.5}$ infiltration process may affect the toxicity of $\mathrm{PM}_{2.5}$ of outdoor origin in indoor environments.

Acknowledgements This work was supported by the US Environmental Protection Agency, Office of Radiation and Indoor Air, Indoor Environments Division. The authors were also supported in part by an ASHRAE New Investigator Award and in part by the US Environmental Protection Agency under Assistance Agreement No. \#83575001 awarded to Illinois Institute of Technology. The views expressed in this document are solely those of the authors and do not necessarily reflect those of the Agency. EPA does not endorse any products or commercial services mentioned in this publication. The authors would like to acknowledge Torkan Fazli for providing outputs from her REIAQ model data set.

Funding This work was supported by the US Environmental Protection Agency, Office of Radiation and Indoor Air, Indoor Environments Division. BS and PA were also supported in part by an ASHRAE New Investigator Award and in part by the US Environmental Protection Agency under Assistance Agreement No. \#83575001 awarded to Illinois Institute of Technology. The views expressed in this document are solely those of the authors and do not necessarily reflect those of the Agency. EPA does not endorse any products or commercial services mentioned in this publication.

\section{Compliance with ethical standards}

Conflict of interest The authors declare that they have no conflict of interest.

Open Access This article is licensed under a Creative Commons Attribution 4.0 International License, which permits use, sharing, adaptation, distribution and reproduction in any medium or format, as long as you give appropriate credit to the original author(s) and the source, provide a link to the Creative Commons license, and indicate if changes were made. The images or other third party material in this article are included in the article's Creative Commons license, unless indicated otherwise in a credit line to the material. If material is not included in the article's Creative Commons license and your intended use is not permitted by statutory regulation or exceeds the permitted use, you will need to obtain permission directly from the copyright holder. To view a copy of this license, visit http://creativecommons. org/licenses/by/4.0/.

\section{References}

1. Brook RD, Rajagopalan S, Pope CA, Brook JR, Bhatnagar A, Diez-Roux AV, et al. Particulate matter air pollution and cardiovascular disease. Circulation. 2010;121:2331-78.

2. Di Q, Wang Y, Zanobetti A, Wang Y, Koutrakis P, Choirat C, et al. Air pollution and mortality in the medicare population. $\mathrm{N}$ Engl J Med. 2017;376:2513-22.

3. Dockery DW, Pope CA 3rd, Xu X, Spengler JD, Ware JH, Fay $\mathrm{ME}$, et al. An association between air pollution and mortality in six U.S. cities. N Engl J Med. 1993;329:1753-9.

4. Gharibvand L, Shavlik D, Ghamsary M, Beeson WL, Soret S, Knutsen $\mathrm{R}$, et al. The association between ambient fine particulate air pollution and lung cancer incidence: results from the AHSMOG-2 study. Environ Health Perspect. 2017;125:378-84.

5. Krewski D, Jerrett M, Burnett RT, Ma R, Hughes E, Shi Y, et al. Extended follow-up and spatial analysis of the American Cancer Society study linking particulate air pollution and mortality. Res Rep Health Eff Inst. 2009;5-114; discussion 115-36.

6. Pope CA, Burnett RT, Thun MJ, Calle EE, Krewski D, Ito K, et al. Lung cancer, cardiopulmonary mortality, and long-term exposure to fine particulate air pollution. JAMA J Am Med Assoc. 2002;287:1132-41.

7. Pope CA, Dockery DW. Health effects of fine particulate air pollution: lines that connect. J Air Waste Manag Assoc. 2006;56:709-42.

8. Shi L, Zanobetti A, Kloog I, Coull BA, Koutrakis P, Melly SJ, et al. Low-concentration PM2.5 and mortality: estimating acute and chronic effects in a population-based study. Environ Health Perspect. 2015;124. https://doi.org/10.1289/ehp.1409111.

9. US EPA. Integrated science assessment for particulate matter. Research Triangle Park, NC: National Center for Environmental Assessment; 2009.

10. Brown KW, Sarnat JA, Koutrakis P. Concentrations of PM2.5 mass and components in residential and non-residential indoor microenvironments: The Sources and Composition of Particulate Exposures study. J Expo Sci Environ Epidemiol. 2012;22:161-72.

11. Burke JM, Zufall MJ, Ozkaynak H. A population exposure model for particulate matter: case study results for $\operatorname{PM}(2.5)$ in Philadelphia, PA. J Expo Anal Environ Epidemiol. 2001;11:470-89.

12. Clayton CA, Perritt RL, Pellizzari ED, Thomas KW, Whitmore RW, Wallace LA, et al. Particle Total Exposure Assessment Methodology (PTEAM) study: distributions of aerosol and elemental concentrations in personal, indoor, and outdoor air samples in a southern California community. J Expo Anal Environ Epidemiol. 1993;3:227-50.

13. Meng QY, Turpin BJ, Korn L, Weisel CP, Morandi M, Colome $\mathrm{S}$, et al. Influence of ambient (outdoor) sources on residential indoor and personal PM2.5 concentrations: Analyses of RIOPA data. J Expo Anal Environ Epidemiol. 2005;15:17-28.

14. Van Ryswyk K, Wheeler AJ, Wallace L, Kearney J, You H, Kulka R, et al. Impact of microenvironments and personal activities on personal PM2.5 exposures among asthmatic children. J Expo Sci Environ Epidemiol. 2014;24:260-8.

15. Wallace L. Indoor particles: a review. J Air Waste Manag Assoc. 1996;46:98-126.

16. Cao Y, Frey HC. Geographic differences in inter-individual variability of human exposure to fine particulate matter. Atmos Environ. 2011;45:5684-91.

17. Klepeis NE, Nelson WC, Ott WR, Robinson JP, Tsang AM, Switzer P, et al. The National Human Activity Pattern Survey (NHAPS): a resource for assessing exposure to environmental pollutants. J Expo Anal Environ Epidemiol. 2001;11:231-52. 
18. Spalt EW, Curl CL, Allen RW, Cohen M, Williams K, Hirsch $\mathrm{JA}$, et al. Factors influencing time-location patterns and their impact on estimates of exposure: the Multi-Ethnic Study of Atherosclerosis and Air Pollution (MESA Air). J Expo Sci Environ Epidemiol. 2016;26:341-8.

19. Allen RW, Adar SD, Avol E, Cohen M, Curl CL, Larson T, et al. Modeling the residential infiltration of outdoor PM2.5 in the Multi-Ethnic Study of Atherosclerosis and Air Pollution (MESA Air). Environ Health Perspect. 2012;120:824-30.

20. Chen C, Zhao B. Review of relationship between indoor and outdoor particles: I/O ratio, infiltration factor and penetration factor. Atmos Environ. 2011;45:275-88.

21. Long CM, Suh HH, Catalano PJ, Koutrakis P. Using time- and size-resolved particulate data to quantify indoor penetration and deposition behavior. Environ Sci Technol. 2001;35:2089-99.

22. MacNeill M, Kearney J, Wallace L, Gibson M, Héroux ME, Kuchta J, et al. Quantifying the contribution of ambient and indoor-generated fine particles to indoor air in residential environments. Indoor Air. 2014;24:362-75.

23. MacNeill M, Wallace L, Kearney J, Allen RW, Van Ryswyk K, Judek S, et al. Factors influencing variability in the infiltration of PM2.5 mass and its components. Atmos Environ. 2012;61:518-32.

24. Wallace L, Williams R. Use of personal-indoor-outdoor sulfur concentrations to estimate the infiltration factor and outdoor exposure factor for individual homes and persons. Environ Sci Technol. 2005;39:1707-14.

25. Wallace L. Indoor sources of ultrafine and accumulation mode particles: size distributions, size-resolved concentrations, and source strengths. Aerosol Sci Technol. 2006;40:348-60.

26. Wallace LA, Emmerich SJ, Howard-Reed C. Source strengths of ultrafine and fine particles due to cooking with a gas stove. Environ Sci Technol. 2004;38:2304-11.

27. Wallace LA, Mitchell H, O’Connor GT, Neas L, Lippmann M, Kattan M, et al. Particle concentrations in inner-city homes of children with asthma: the effect of smoking, cooking, and outdoor pollution. Environ Health Perspect. 2003;111:1265-72.

28. Afshari A, Matson U, Ekberg LE. Characterization of indoor sources of fine and ultrafine particles: a study conducted in a fullscale chamber. Indoor Air. 2005;15:141-50.

29. Ott WR, Siegmann HC. Using multiple continuous fine particle monitors to characterize tobacco, incense, candle, cooking, wood burning, and vehicular sources in indoor, outdoor, and in-transit settings. Atmos Environ. 2006;40:821-43.

30. He C, Morawska L, Taplin L. Particle emission characteristics of office printers. Environ Sci Technol. 2007;41:6039-45.

31. He C, Morawska L, Wang H, Jayaratne R, McGarry P, Richard Johnson G, et al. Quantification of the relationship between fuser roller temperature and laser printer emissions. J Aerosol Sci. 2010;41:523-30.

32. Ferro AR, Kopperud RJ, Hildemann LM. Source strengths for indoor human activities that resuspend particulate matter. Environ Sci Technol. 2004;38:1759-64.

33. Qian J, Ferro AR. Resuspension of dust particles in a chamber and associated environmental factors. Aerosol Sci Technol. 2008;42:566-78.

34. Waring MS. Secondary organic aerosol in residences: predicting its fraction of fine particle mass and determinants of formation strength. Indoor Air. 2014;24:376-89.

35. Hänninen $\mathrm{O}$, Rumrich I, Asikainen A. Challenges in estimating health effects of indoor exposures to outdoor particles: Considerations for regional differences. Sci Total Environ. 2017;589:130-5.

36. Yeh S, Small MJ. Incorporating exposure models in probabilistic assessment of the risks of premature mortality from particulate matter. J Expo Anal Environ Epidemiol. 2002;12:389-403.
37. IEc. Health and Welfare Benefits Analyses to Support the Second Section 812 Benefit-Cost Analysis of the Clean Air Act. Cambridge, MA: Industrial Economics, Inc.; 2011.

38. Fann N, Lamson AD, Anenberg SC, Wesson K, Risley D, Hubbell BJ. Estimating the national public health burden associated with exposure to ambient PM2.5 and ozone. Risk Anal. 2012;32:81-95.

39. Fann N, Gilmore EA, Walker K. Characterizing the long-term PM 2.5 concentration-response function: comparing the strengths and weaknesses of research synthesis approaches: characterizing long-term PM 2.5 concentration-response function. Risk Anal. 2016;36:1693-707.

40. Fann N, Fulcher CM, Baker K. The recent and future health burden of air pollution apportioned across U.S. sectors. Environ Sci Technol. 2013;47:3580-9.

41. Penn SL, Arunachalam S, Woody M, Heiger-Bernays W, Tripodis Y, Levy JI. Estimating state-specific contributions to PM2.5- and O3-related health burden from residential combustion and electricity generating unit emissions in the United States. Environ Health Perspect. 2016;125. https://doi.org/10. 1289/EHP550.

42. Fann N, Kim S-Y, Olives C, Sheppard L. Estimated changes in life expectancy and adult mortality resulting from declining PM2.5 exposures in the contiguous United States: 1980-2010. Environ Health Perspect. 2017;125. https://doi.org/10.1289/ EHP507.

43. Lelieveld J, Barlas C, Giannadaki D, Pozzer A. Model calculated global, regional and megacity premature mortality due to air pollution. Atmos Chem Phys. 2013;13:7023-37.

44. Anenberg SC, Horowitz LW, Tong DQ, West JJ. An Estimate of the Global Burden of Anthropogenic Ozone and Fine Particulate Matter on Premature Human Mortality Using Atmospheric Modeling. Environ Health Perspect. 2010;118:1189-95.

45. Nasari MM, Szyszkowicz M, Chen H, Crouse D, Turner MC, Jerrett M, et al. A class of non-linear exposure-response models suitable for health impact assessment applicable to large cohort studies of ambient air pollution. Air Qual Atmosphere Health. 2016;9:961-72.

46. Chan WR, Parthasarathy S, Fisk WJ, McKone TE. Estimated effect of ventilation and filtration on chronic health risks in U.S. offices, schools, and retail stores. Indoor Air. 2016;26:331-43.

47. Fisk WJ, Chan WR Effectiveness and cost of reducing particlerelated mortality with particle filtration. Indoor Air 2017. https:// doi.org/10.1111/ina.12371.

48. Logue JM, Price PN, Sherman MH, Singer BC. A method to estimate the chronic health impact of air pollutants in U.S. residences. Environ Health Perspect. 2012;120:216-22.

49. Montgomery JF, Reynolds CCO, Rogak SN, Green SI. Financial implications of modifications to building filtration systems. Build Environ. 2015;85:17-28.

50. Zhao D, Azimi P, Stephens B. Evaluating the long-term health and economic impacts of central residential air filtration for reducing premature mortality associated with indoor fine particulate matter (PM2.5) of outdoor origin. Int J Environ Res Public Health. 2015;12:8448-79.

51. Burnett RT, Pope CA III, Ezzati M, Olives C, Lim SS, Mehta S, et al. An integrated risk function for estimating the global burden of disease attributable to ambient fine particulate matter exposure. Environ Health Perspect. 2014. https://doi.org/10.1289/ehp. 1307049.

52. Apte JS, Marshall JD, Cohen AJ, Brauer M. Addressing global mortality from ambient PM2.5. Environ Sci Technol. 2015;49:8057-66.

53. Lelieveld J, Evans JS, Fnais M, Giannadaki D, Pozzer A. The contribution of outdoor air pollution sources to premature mortality on a global scale. Nature. 2015;525:367-71. 
54. Rohde RA, Muller RA. Air pollution in China: mapping of concentrations and sources. PLoS ONE. 2015;10:e0135749.

55. Cohen AJ, Brauer M, Burnett R, Anderson HR, Frostad J, Estep, et al. Estimates and 25-year trends of the global burden of disease attributable to ambient air pollution: an analysis of data from the Global Burden of Diseases Study 2015. Lancet. 2017;389:1907-18.

56. Chowdhury S, Dey S, Smith KR Ambient PM2.5 exposure and expected premature mortality to 2100 in India under climate change scenarios. Nat Commun 2018; 9. https://doi.org/10.1038/ s41467-017-02755-y.

57. Burnett R, Chen H, Szyszkowicz M, Fann N, Hubbell B, Pope $\mathrm{CA}$, et al. Global estimates of mortality associated with longterm exposure to outdoor fine particulate matter. Proc Natl Acad Sci. 2018;115:9592-9597.

58. Ebelt ST, Wilson WE, Brauer M. Exposure to ambient and nonambient components of particulate matter: a comparison of health effects. Epidemiology. 2005;16:396-405.

59. Koenig JQ, Mar TF, Allen RW, Jansen K, Lumley T, Sullivan $\mathrm{JH}$, et al. Pulmonary effects of indoor- and outdoor-generated particles in children with asthma. Environ Health Perspect. 2005;113:499-503.

60. Monn C, Becker S. Cytotoxicity and induction of proinflammatory cytokines from human monocytes exposed to fine (PM2.5) and coarse particles (PM10-2.5) in outdoor and indoor air. Toxicol Appl Pharmacol. 1999;155:245-52.

61. Long CM, Suh HH, Kobzik L, Catalano PJ, Ning YY, Koutrakis P. A pilot investigation of the relative toxicity of indoor and outdoor fine particles: in vitro effects of endotoxin and other particulate properties. Environ Health Perspect. 2001;109:1019-26.

62. Ebelt ST, Petkau AJ, Vedal S, Fisher TV, Brauer M. Exposure of chronic obstructive pulmonary disease patients to particulate matter: relationships between personal and ambient air concentrations. J Air Waste Manag Assoc. 2000;50:1081-94.

63. Brook RD, Bard RL, Burnett RT, Shin HH, Vette A, Croghan C, et al. Differences in blood pressure and vascular responses associated with ambient fine particulate matter exposures measured at the personal versus community level. Occup Environ Med. 2011;68:224-30.

64. Adams HS, Nieuwenhuijsen MJ, Colvile RN, McMullen MAS, Khandelwal P. Fine particle (PM2.5) personal exposure levels in transport microenvironments, London, UK. Sci Total Environ. 2001;279:29-44.

65. Kingham S, Meaton J, Sheard A, Lawrenson O. Assessment of exposure to traffic-related fumes during the journey to work. Transp Res Part Transp Environ. 1998;3:271-4.

66. Butler DA, Madhavan G, Alper J. Health risks of indoor exposure to particulate matter: workshop summary. Washington, D. C.: National Academies Press; 2016. https://doi.org/10.17226/ 23531.

67. Avery CL, Mills KT, Williams R, McGraw KA, Poole C, Smith $\mathrm{RL}$, et al. Estimating error in using residential outdoor PM2.5 concentrations as proxies for personal exposures: a metaanalysis. Environ Health Perspect. 2010;118:673-8.

68. Avery CL, Mills KT, Williams R, McGraw KA, Poole C, Smith RL, et al. Estimating error in using ambient PM2.5 concentrations as proxies for personal exposures: a review. Epidemiology. 2010;21:215-23.

69. Baxter LK, Crooks JL, Sacks JD. Influence of exposure differences on city-to-city heterogeneity in PM2.5-mortality associations in US cities. Environ Health 2017;16. https://doi.org/10. 1186/s12940-016-0208-y.

70. Baxter LK, Wright RJ, Paciorek CJ, Laden F, Suh HH, Levy JI. Effects of exposure measurement error in the analysis of health effects from traffic-related air pollution. J Expo Sci Environ Epidemiol. 2010;20:101-11.

71. Baxter LK, Franklin M, Özkaynak H, Schultz BD, Neas LM. The use of improved exposure factors in the interpretation of fine particulate matter epidemiological results. Air Qual Atmosphere Health. 2013;6:195-204.

72. Baxter LK, Sacks JD. Clustering cities with similar fine particulate matter exposure characteristics based on residential infiltration and in-vehicle commuting factors. Sci Total Environ. 2014;470-471:631-8.

73. Hodas N, Meng Q, Lunden MM, Rich DQ, Özkaynak H, Baxter LK, et al. Variability in the fraction of ambient fine particulate matter found indoors and observed heterogeneity in health effect estimates. J Expo Sci Environ Epidemiol. 2012;22:448-54.

74. Hodas N, Turpin BJ, Lunden MM, Baxter LK, Özkaynak H, Burke J, et al. Refined ambient PM2.5 exposure surrogates and the risk of myocardial infarction. J Expo Sci Environ Epidemiol. 2013;23:573-80.

75. Hoek G, Krishnan RM, Beelen R, Peters A, Ostro B, Brunekreef $\mathrm{B}$, et al. Long-term air pollution exposure and cardio- respiratory mortality: a review. Environ Health. 2013;12. https://doi.org/10. 1186/1476-069X-12-43.

76. Meng QY, Turpin BJ, Polidori A, Lee JH, Weisel C, Morandi M, et al. PM2.5 of ambient origin: estimates and exposure errors relevant to PM epidemiology. Environ Sci Technol. 2005;39:5105-12.

77. Sarnat JA, Sarnat SE, Flanders WD, Chang HH, Mulholland J, Baxter L, et al. Spatiotemporally resolved air exchange rate as a modifier of acute air pollution-related morbidity in Atlanta. J Expo Sci Environ Epidemiol. 2013;23:606-15.

78. Sheppard L, Burnett RT, Szpiro AA, Kim S-Y, Jerrett M, Pope CA, et al. Confounding and exposure measurement error in air pollution epidemiology. Air Qual Atmosphere Health. 2012;5:203-16.

79. Jones RR, Özkaynak H, Nayak SG, Garcia V, Hwang S-A, Lin S. Associations between summertime ambient pollutants and respiratory morbidity in New York City: comparison of results using ambient concentrations versus predicted exposures. J Expo Sci Environ Epidemiol. 2013;23:616-26.

80. Mannshardt E, Sucic K, Jiao W, Dominici F, Frey HC, Reich B, et al. Comparing exposure metrics for the effects of fine particulate matter on emergency hospital admissions. J Expo Sci Environ Epidemiol. 2013;23:627-36.

81. Rackes A, Ben-David T, Waring MS. Outcome-based ventilation: a framework for assessing performance, health, and energy impacts to inform office building ventilation decisions. Indoor Air. 2018. https://doi.org/10.1111/ina.12466.

82. U.S. EPA. Air trends: particulate matter (PM2.5) trends. 2016. https://www.epa.gov/air-trends/particulate-matter-pm25-trends.

83. Roman HA, Walker KD, Walsh TL, Conner L, Richmond HM, Hubbell BJ, et al. Expert judgment assessment of the mortality impact of changes in ambient fine particulate matter in the U.S. Environ Sci Technol. 2008;42:2268-74.

84. Crouse DL, Peters PA, van Donkelaar A, Goldberg MS, Villeneuve PJ, Brion $\mathrm{O}$, et al. Risk of nonaccidental and cardiovascular mortality in relation to long-term exposure to low concentrations of fine particulate matter: a Canadian nationallevel cohort study. Environ Health Perspect. 2012;120:708-14.

85. Schwartz J, Coull B, Laden F, Ryan L. The effect of dose and timing of dose on the association between airborne particles and survival. Environ Health Perspect. 2007;116:64-69.

86. Pinault L, Tjepkema M, Crouse DL, Weichenthal S, van Donkelaar A, Martin RV, et al. Risk estimates of mortality attributed to low concentrations of ambient fine particulate matter in the Canadian community health survey cohort. Environ Health. 2016;15. https://doi.org/10.1186/s12940-016-0111-6. 
87. CDC. National Center for Health Statistics WONDER Online Database: Compressed Mortality File 1999-2016 Series 20, No. 2V. CDC WONDER. 2017. https://wonder.cdc.gov/cmf-icd10. htm (accessed 22 May 2018).

88. Dockery DW, Spengler JD. Indoor-outdoor relationships of respirable sulfates and particles. Atmos Environ 1967. 1981;15:335-43.

89. Fazli T, Stephens B. Development of a nationally representative set of combined building energy and indoor air quality models for U.S. residences. Build Environ. 2018;136:198-212.

90. Touchie MF, Siegel JA. Residential HVAC runtime from smart thermostats: characterization, comparison, and impacts. Indoor Air. 2018. https://doi.org/10.1111/ina.12496.

91. Cox L. Rethinking the meaning of concentration-response functions and the estimated burden of adverse health effects attributed to exposure concentrations: invited commentary. Risk Anal. 2016;36:1770-9.

92. Dominici F, Greenstone M, Sunstein CR. Particulate matter matters. Science. 2014;344:257-9.

93. Frey HC. Dose-response models are conditional on determination of causality: invited commentary. Risk Anal. 2016;36:1751-4.

94. McClellan RO. Providing context for ambient particulate matter and estimates of attributable mortality: invited commentary. Risk Anal. 2016;36:1755-65.

95. Pope CA, Cropper M, Coggins J, Cohen A. Health benefits of air pollution abatement policy: Role of the shape of the concentration-response function. J Air Waste Manag Assoc. 2015;65:516-22.

96. Franklin M, Koutrakis P, Schwartz P. The role of particle composition on the association between PM2.5 and mortality. Epidemiology. 2008;19:680-9.

97. Ostro B, Lipsett M, Reynolds P, Goldberg D, Hertz A. Longterm exposure to constituents of fine particulate air pollution and mortality: results from the California Teachers Study. Environ Health Perspect. 2010;118:363-9.

98. Ostro B, Feng W-Y, Broadwin R, Green S, Lipsett M. The effects of components of fine particulate air pollution on mortality in California: results from CALFINE. Environ Health Perspect. 2006;115:13-19.
99. Shin HH, Cohen AJ, Pope CA, Ezzati M, Lim SS, Hubbell BJ, et al. Meta-analysis methods to estimate the shape and uncertainty in the association between long-term exposure to ambient fine particulate matter and cause-specific mortality over the global concentration range: global particle pollution risks and their uncertainty. Risk Anal. 2016;36:1813-25.

100. Vodonos A, Awad YA, Schwartz J. The concentration-response between long-term PM 2.5 exposure and mortality; A metaregression approach. Environ Res. 2018;166:677-89.

101. Allen RW, Carlsten C, Karlen B, Leckie S, Eeden S, van, Vedal $S$, et al. An air filter intervention study of endothelial function among healthy adults in a woodsmoke-impacted community. Am J Respir Crit Care Med. 2011;183:1222-30.

102. Bräuner EV, Forchhammer L, Moller P, Barregard L, Gunnarsen $\mathrm{L}$, Afshari A, et al. Indoor particles affect vascular function in the aged: an air filtration-based intervention study. Am J Respir Crit Care Med. 2008;177:419-25.

103. Chuang H-C, Ho K-F, Lin L-Y, Chang T-Y, Hong G-B, Ma C$\mathrm{M}$, et al. Long-term indoor air conditioner filtration and cardiovascular health: A randomized crossover intervention study. Environ Int. 2017;106:91-96.

104. Kajbafzadeh M, Brauer M, Karlen B, Carlsten C, van Eeden S, Allen RW. The impacts of traffic-related and woodsmoke particulate matter on measures of cardiovascular health: a HEPA filter intervention study. Occup Environ Med. 2015; 72:394-400.

105. Karottki DG, Spilak M, Frederiksen M, Gunnarsen L, Brauner EV, Kolarik B, et al. An indoor air filtration study in homes of elderly: cardiovascular and respiratory effects of exposure to particulate matter. Environ Health. 2013;12. https://doi.org/10. 1186/1476-069X-12-116.

106. Lin L-Y, Chen H-W, Su T-L, Hong G-B, Huang L-C, Chuang K$\mathrm{J}$. The effects of indoor particle exposure on blood pressure and heart rate among young adults: an air filtration-based intervention study. Atmos Environ. 2011;45:5540-4.

107. Weichenthal S, Mallach G, Kulka R, Black A, Wheeler A, You $\mathrm{H}$, et al. A randomized double-blind crossover study of indoor air filtration and acute changes in cardiorespiratory health in a First Nations community. Indoor Air. 2013;23:175-84. 